\title{
Evolving Payment Platform for Developing Countries
}

\author{
http://dx.doi.org/10.3991/ijim.v7i2.2462 \\ Rodrigue Carlos Nana Mbinkeu \\ University of Yaounde I, Yaounde, Cameroon \\ University of Modena, Italy
}

\begin{abstract}
This article shows the impact of the growing adoption of mobile phones in the field of money transfer in Africa but also their uses in the field of retail payments or micropayments that is financial transaction from person to person (P2P) for small amounts. We show how these innovations will continue to improve the quality of life of Africans especially those in rural areas. We present M-Pesa as a mobile payment system which has had great success in Kenya. We identify the fundamental principles of success thus this enabled us to create an ECOPAY platform which is an innovative mobile payment system. Our platform provides different types of m-payment like as B2C, B2B or P2P using the mobile phone or others devices. Each transaction is secure by using encrypted message and encrypted connection between the devices and the ECOPAY servers.
\end{abstract}

Index Terms-e-commerce, m-payment, transfer, money, m-wallet, mobile phone

\section{INTRODUCTION}

During the last few decades, the ICT sector in Africa has been rapidly evolving. In some countries, information technology is emerging to boost economies. This evolution is due to the widespread adoption of information technology on the continent. The number of mobile subscriptions in use worldwide, both pre-paid and postpaid, has grown from fewer than 1 billion in 2000 to over 6 billion now, of which nearly 5 billion are in developing countries [1]. In this context, African banks and telecom operators have started to integrate their development strategies in achieving the technological infrastructure including: mobile payment, also called the M-Payment. This technology offers new perspectives in Africa in the field of trade in goods and services. Mobile payments, i.e. payments made from your mobile phone, will continue to take their share of cashless payments for various reasons in Africa.

The aim of this paper is to propose an analysis of this new technology in the African context and to understand what the principles behind the success of these $M$ payment projects are. Secondly, we present our mobile payment solution.

The paper starts with a brief discussion about Mpayment in Africa and opportunities. We study the successful case of the mobile payment system called M-Pesa and consequently we derive the basic principles of $\mathrm{m}$ payment projects. Section 3 presents the general ECOPAY platform and its innovations in terms of user services, followed by conclusions.

\section{Mobile PAyment In AFRICA}

The main components of the mobile payment system are the money transfer applications and network infrastructure (internet and gsm). Banks, mobile operators, trusted third parties are the main players in mobile payment systems [1]. People will probably be more likely to make financial transactions through M-Payment solutions without opening a bank account. Therefore this technology resolves a problem of low banking penetration in Africa [3]. The development of this new electronic payment method is closely related to the evolution of new information technologies, telecommunications and high mobile phone penetration in the daily lives of Africans. It eases the adoption of M-payment in Africa and encourages banks to create new services for users directly accessible on mobile phones. It is M-Banking.

With the M-Banking, the user accesses several services including account balances, viewing account history and makes financial transactions. One of the features of $\mathrm{M}$ Banking is the ability to rapidly deal with suspicious transactions (credit card stolen) even when they are miles away from their nearest branch.

As for the M-Payment, it offers several services such as, telephone recharges, bill payments, retail payments and more. The advantage of M-Payment is the fact that several functions work with both traditional mobile phones and smartphones.

The basic premise is that mobile payments offer a way for people with low incomes or the unbanked to make financial transactions without getting involved with a traditional financial institution $[1,8]$.The M-Payment is more advantageous to rural populations [3]. This technology will create competition with older money transfer companies and this will continue to reduce the transfer rates between cities and rural areas in Africa. Africans will benefit from local services with relatively low transaction costs, easier accessibility to financial services. The time savings are immeasurable by reducing the movement of people especially those located in inaccessible areas. Mpayment offers several advantages including simplicity and accessibility to the service at any time. This will lead to poverty reduction [3]

\section{A. Analysis of the Kenyan experience: $M$-Pesa}

Mobile financial services are among the most promising mobile applications in the developing world [1, 11]. Mobile money could become a general platform that transforms entire economies, as it is adopted across commerce, health care, agriculture, and other sectors. To 
date, at least 110 money mobile systems have been deployed, with more than 40 million users [1, 7]. The most well-known system, M-PESA, started in Kenya and is now operational in six countries; it has 20 million users who transferred \$500 million a month during 2011and are served by more than 28,000 agents [1, 4, 8].

M-Pesa users can deposit money into their own account, and then make transfers to a contact or withdraw money at a number of bank branches or agents in the country. The amount transferred is cheaper than transfers made in traditional networks. For recipients, several options are available like withdrawing the total sum from an agent. The registered users are managed directly by the M-Pesa system on dedicated accounts also called m-wallet accounts, thus it is not necessary for the user to have a bank account. The subscription service is provided free of charge. Studies showed that the majority of consumers use the service for transferring money to families or close friends [8]. Among the criticisms, consumers mention frequent cases of offices or agents who are short of cash, some cases of attempted fraud and occasional complications on the network. However, the general opinion of consumers about M-Pesa is remarkably positive. M-Pesa has had a significant impact on the domestic transfer market. M-Pesa services have expanded to include bill payments, bundled payments of wages and payment of school fees. M-Pesa is a service offered to subscribers by the first mobile operator called Safaricom in Kenya [4]. According to the International Monetary Fund (IMF) in 2011, M-Pesa has handled more transactions in Kenya as Western Union worldwide [5].

Taking into account the Kenyan experience, it is important to note that the launch of an m-payment service should respect three basic principles [6]:

- A large volume of transactions must be able to compensate for lower rates;

- A higher speed acquisition of new customers and agents to reach a critical mass of registered users enabling the service to be operating. As a reminder, money transfer for example, requires that the sender, the receiver of the money transfer and agents have access to m-payment services.

- A Geographic coverage is important to make the service available anywhere at any time.

- In response, five conditions require special analysis to confirm the launch of a mobile payment [6]:

1 The latent demand for transactions;

2 The quality of existing services;

3 The legislations;

4 The mobile services market;

5 The network of agents and partners.

There are also other operators such as Orange money, Airtel money, and MTN money, which are very active in Africa and have also developed their mobile payment solutions.

\section{The General ARChitecture of ECOPAY PLATFORM}

The ECOPAY Platform marks our efforts to help bring financial services to consumers in all corners of Cameroon via mobile money services and ECOPAY Network Partners such as banks, microfinance institutions and agents. The ECOPAY platform will be open to all mobile users, regardless of their network, and will allow the daily to any Cameroonian mobile phone number.

Our platform takes into consideration that mobile phones are multifunctional devices which allow for a variety of communication methods. These range from ubiquitous voice and SMS applications to more sophisticated solutions such as software applications or web browsers. To be a viable solution for mobile money, the applications should ideally be universally available (including the cheapest mobile phones) and must be secure. For these reasons, the ECOPAY client applications will be compatible with a range of smartphone, while those without a smartphone can use a simple client built with Java Micro-edition to access our services (figure 1). ECOPAY Client on the phone is controlled by a five-digit PIN.

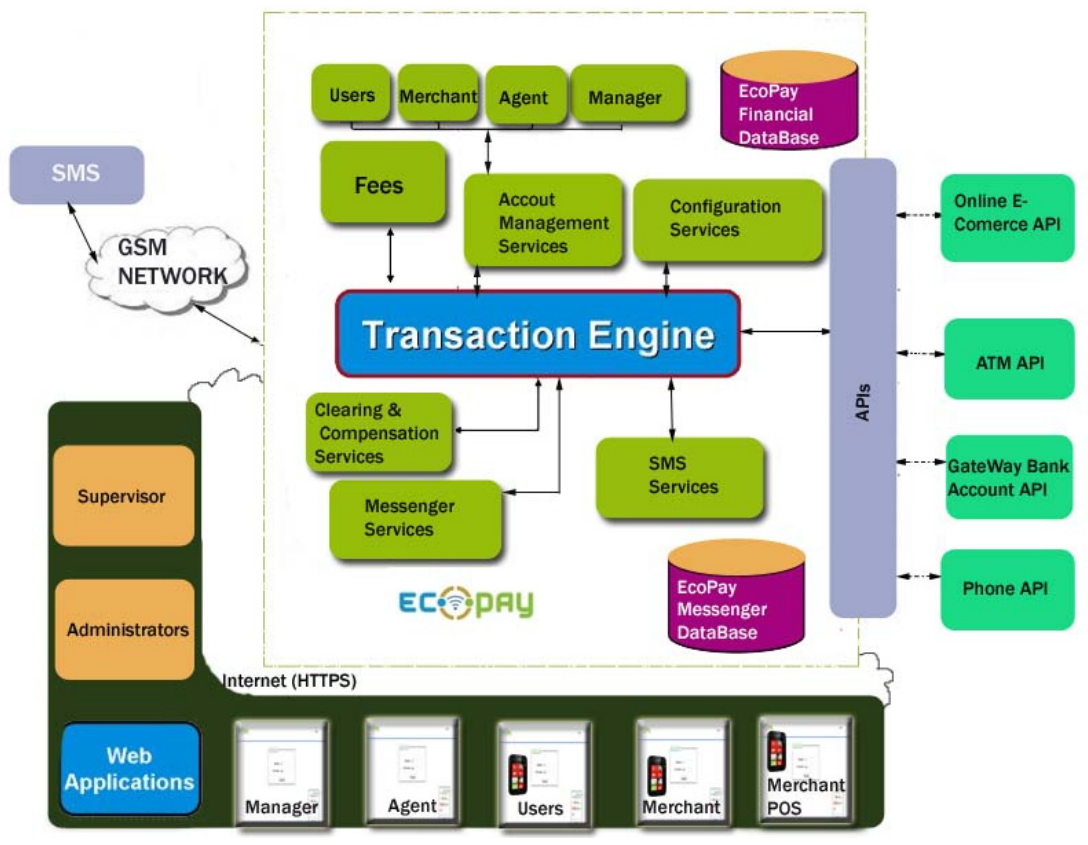

Figure 1. EcoPay Architecture 
Users can also access their m-wallet by connecting with computers (web browsers) and they can access a variety of services. The general architecture of our platform ensures that banks of all shapes and sizes can use it. The important aspect of our platform is the fact that it allows more banks and microfinance institutions to interact with each other through our transaction services, clearing and compensation engine (figure 1).Therefore, ECOPAY users can deposit or withdraw money even in other institutions or agents where their m-wallets are not affiliated. Our partner network helps to make the service available everywhere at anytime. All partners of our network can communicate with each other by using our built-in chat or messenger module (figure 1).

During the registration process, users have the choice between two types of m-wallet: Standard m-wallet or Business m-wallet. A business m-wallet is the account which allows user to receive payments from customers in their shops or websites.

Payment in the shops can be made by using the mobile phone of merchant (section III.A), while the payment on websites are made by using web services. The objective of the proposed architecture is to replace legacy systems used in the retail industry with mobile technologies.

We use a robust set of PHP and Java frameworks and SDKs to develop our platform that are light weight and ideal for programmers who need a simple and elegant toolkit to create full-featured web applications with exceptional performance. The ECOPAY Platform has more technical elements defined in [9, 12] and it is built to work only with one currency at this time.

\section{A. The payment process with ECOPAY}

The mobile payment (m-payment) is considered by many people as the new killer-application that will boost e-/m-commerce; according to Wireless World Forum report [13, 14]. M-payments are payments made using mobile handsets and other devices, either to directly purchase or to authorize payment for goods and services [15].

To subscribe to the ECOPAY services, consumers have to fill out a form. Once the application is approved, the consumer can use ECOPAY for a range of transactions:

- Business-to-Consumer (B2C i.e. for bill payments in markets, shops, website);

- Business-to-Business (B2B i.e. for bill payments between companies or merchants)

- Person-to-Person, P2P m-payments are private transaction between two individuals and it is typically SMS-based (P2P i.e. the user can send money to another individual in any bank or Microfinance Finance Institution of the EcoPay Network Partners, receiver can be nonusers ecopay).

The typical payment transaction between customer and merchant (B2C) on the point-of-sale (POS) using ECOPAY would go like this (see figure 2):

1. The customer gives his mobile phone number to the merchant;

2. The merchant inserts into the ECOPAY mobile application (client), the phone number of customer and the amount to be paid. He then presses the button to validate;
3. ECOPAY mobile client requests the PIN of customer to perform transaction;

4. The customer verifies the amount of debit and inserts his PIN;

5. The merchant confirms the transaction with the ECOPAY mobile Client;

6. ECOPAY mobile Client interacts with the Platform by using Json's call to settle the payment (direct debit);

7. The transaction is performed by updating accounts involved in the payment process and the clearing engine informs the compensation services;

8. The platform sends the result of transaction (sms) to customer by using GSM network;

9. The platform sends the result of transaction (Json's result) to the ECOPAY mobile client;

10. ECOPAY mobile client shows the result of transaction on the screen of mobile (smart) phone.

Through the ECOPAY mobile client, the merchant can view the receipts of the day and view all transactions validated on the screen of the mobile (smart) phone. In general, the payment is made by using mobile phone or smartphone or accessing the account on a computer (see figure 3 for more technical details of transaction). An important success factor for many B2C initiatives is the design of the handset interface [15].

\section{B. How to withdraw money from an ATM with ECOPAY}

Most of the technologies, without integrating with security mechanism originally, have to be redesigned to provide some security services. ATM (Automated teller machines) is one of those technologies [10]. ATM is used by financial institutions to allow their customers to withdraw money even when the bank is closed. We summarize the three major ATM threats:

- Physical, or stealing the cash from an ATM;

- Logical, or the installation of malicious software, and;

- Fraud, or using fake cards and stealing card details in skimming scams.

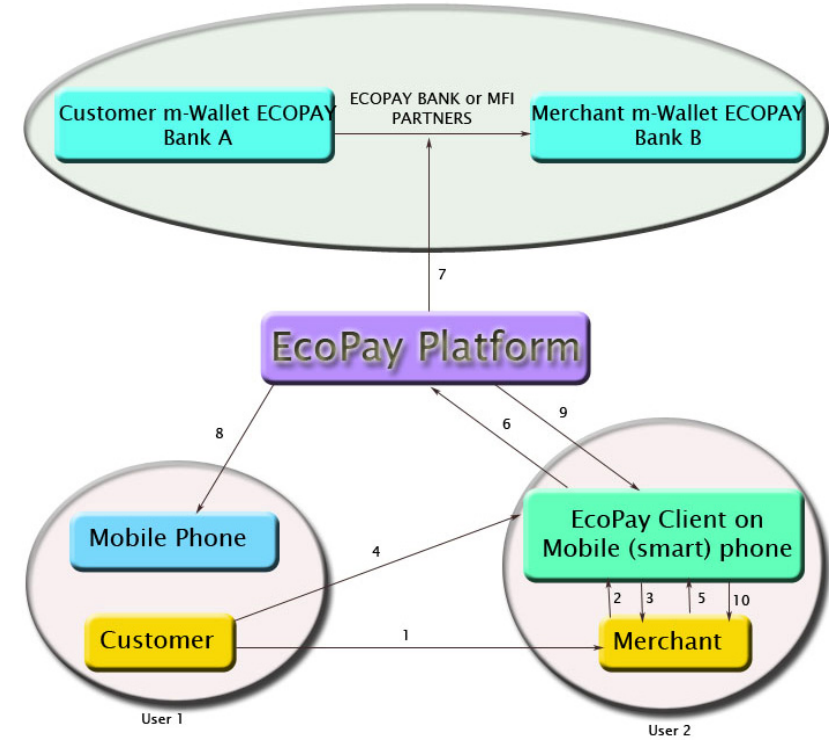

Figure 2. Payment scenario with ECOPAY Platform 


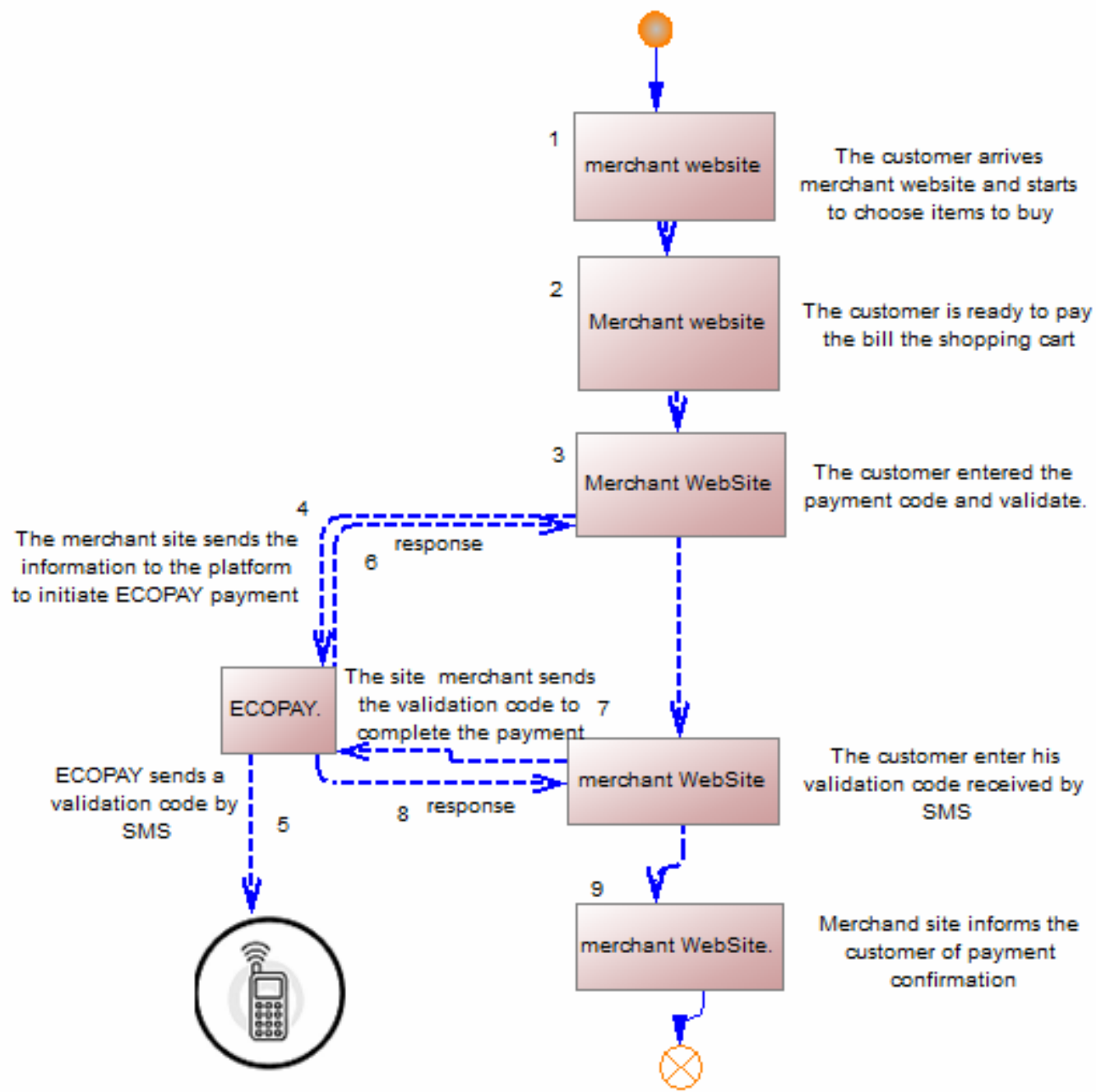

Figure 3. Online Payment scenario on Merchant Websites

The threat of getting your card skimmed is the greatest one and continues to increase [10]. Therefore, for our ecopay project, we designed the new way to withdraw money from ATMs by using the mobile phone (see figure 2). The typical scenario using ECOPAY application on mobile phone would go like this:

1. User launches the ECOPAY application on his mobile phone linked with his m-wallet;

2. User must define the amount to be withdrawn and then user validates the withdraw operation on his mobile;

3. The platform send to User, the random number with sixteen-digit, user has few minutes to withdraw money from ATM;

4. User inserts the random number and his phone number in the ATM and user validates the operation;

5. ATM gives user the exact amount defined before on mobile phone.

With this process, we ensure that ECOPAY users can withdraw money out of their m-wallet from ATM more securely. The other advantage of this approach is the possibility to send money to friends by asking them to go to stay in front the ATM and wait our instructions (we send the random number defined to friends or call to give it).

\section{How to use our online e-Commerce API}

For merchants, charities and organizations, Ecopay ecommerce API is an affordable way to accept payments online. Ecopay e-Commerce API is a programming interface, which allows merchants to automate the process of online payments on their websites. API setup is required in order to use Ecopay as a payment option on websites. Currently Ecopay provides JSON functions. The sequence of pages browsed when using online payment is shown in the figure 3 .

\section{1) Conditions to make shopping on websites}

- The maximum amount spendable will be set by the users in their accounts;

- After validation of the amount spendable, the user gets a payment code;

- The payment code is valid by default for one day but this value can be set up to one month.

- During the purchase, the total amount payable by the users must be less than or equal to the amount associated with the payment code.

\section{Security features of transaction}

While security features do not guarantee a secure system, they are necessary to build a secure system. Our platform includes the following security features: 
PAPER

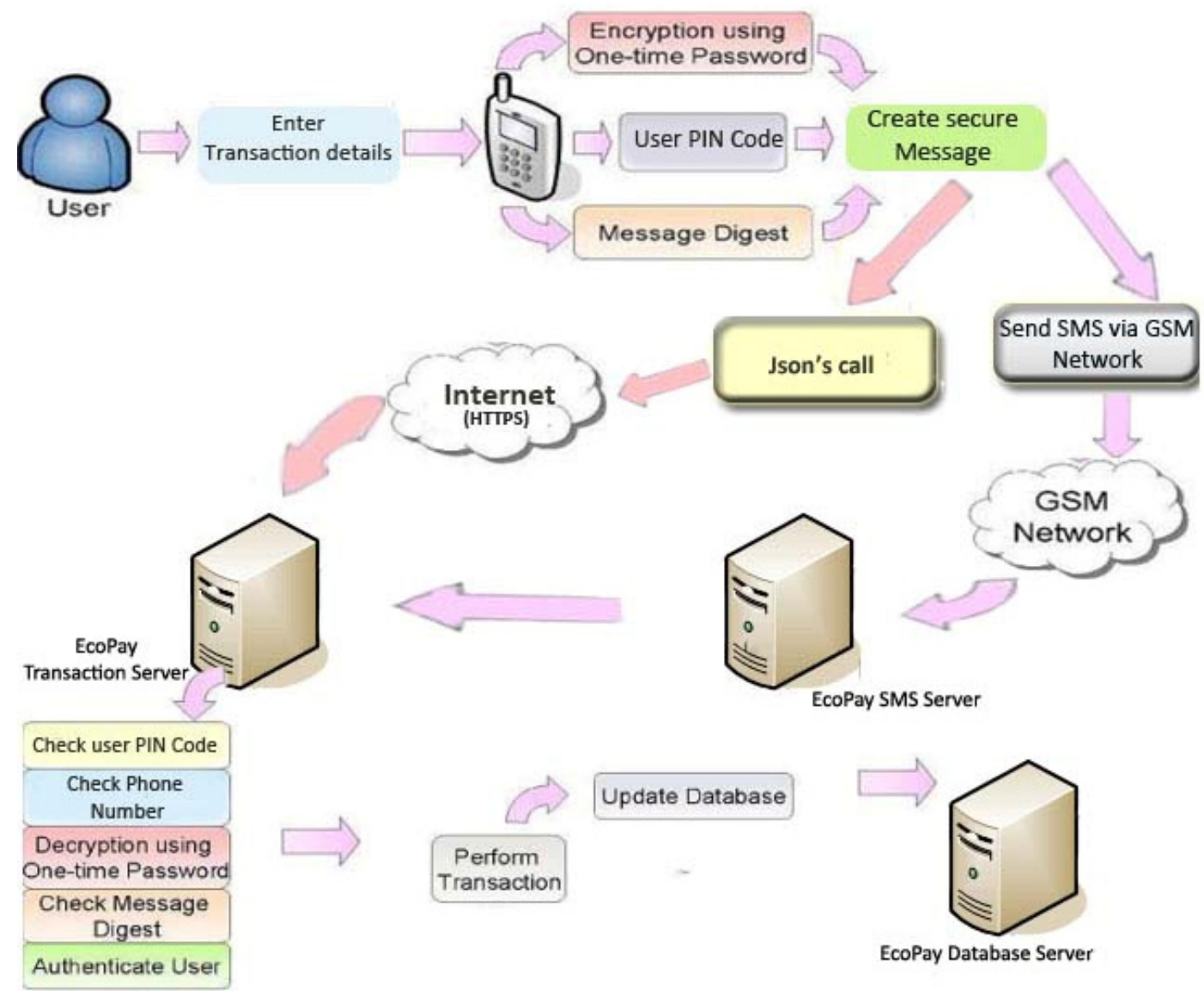

Figure 4. Security features of transaction with mobile phone

- Each type of Transaction requires entering a PIN or validation code;

- All Transactions are encrypted and sent to the ECOPAY Platform;

- ECOPAY Platform receives the transaction order and decrypts it before processing;

- Access to the online account with browser requires two authentication mechanisms (username, password + code session received by sms);

- Internet connections between Users and the ECOPAY Platform are encrypted (HTTPS);

Users receive notifications when their m-wallets are involved in transactions

\section{CONCLUSIONS}

The potential of m-payment in financial inclusion is huge because it allows us to offer a large number of people with low income and the unbanked a range of affordable products that meet their financial needs. Today, m-payment must integrate new services such as online payment. It is for these reasons that we decided to implement a mobile payment solution which proposes new features for users. With the online payment feature, ECOPAY users can purchase products or pay for services in local currency on websites by using their m-wallet accounts.

ECOPAY aims at developing a national mobile payment system. Its innovative business model is based on two key concepts:
- Cooperation of Banks and microfinance institution and

- Social trust relationships since each actor transacts only with his trusted bank or microfinance institution.

It is worth noting that ECOPAY features a distributed approach where banks or microfinance institutions can dynamically join the system with their customer base, something which will allow ECOPAY to grow fast and reach a the critical mass that may establish it as a national payment service.

ECOPAY's project is financed by the Community Investment Corporation limited, an investment and business development company established in Cameroon for the purpose of investing in people, ideas and businesses that represent good long term and beneficial growth opportunities for Cameroon and the African continent.

\section{REFERENCES}

[1] Kevin Donovan. Mobile Money for Financial Inclusion. Information and Communications for development 2012.

[2] Olu Agunloye. Progress on Nigeria’s eGovernment and ePayment Projects, A Presentation at the AITEC Banking and Mobile Money Conference, May 2010.

[3] Wondwossen Taddesse, Tsegai G. Kidan.ePayment: Challenges and Opportunities in Ethiopia.

[4] William Jack, Tavneet Suri. The Economic of M-Pesa, August 2010.

[5] International Monetary Fund. Regional Economic outlook: SubSaharan Africa. World Economic and Financial Surveys. October 2011. 
PAPER

EVOLVING PAYMENT PlATFORM FOR DEVELOPING COUNTRIES

[6] Kurt Salmon et al. Mobile paiement: Enjeux et perspective du développement du m-paiement, 2011.

[7] CGAP. “CGAP Mobile-money Expectation Survey”, September 2010

[8] Alliance For Financial Inclusion. Faciliter les transferts d'argent par téléphone mobile, Le traitement de M-Pesa par la Banque centrale du Kenya, Février 2010.

[9] Manfred Männle. Interoperable Mobile Payment - A Requirements-Based Architecture. Encorus Technologies GmbH; product management Payment Platform.

[10] DevinagaRasiah.ATM Risk Management and Controls. European Journal of Economics, Finance and Administrative Sciences, 2010

[11] Heike Baumüller. Facilitating agricultural technology adoption among the poor: The role of service delivery through mobile phones. ZEF Working Paper Series, 2012.

[12] Jan Ondrus and Yves Pigneur. Architecture for Mobile Payments and Couponing in the Retail Industry. 17th Bled eCommerce Conference Global, 2004.
[13] Sandy Shen. Mobile Payment, Worldwide, 2009-2016, Gartner Research, 2012.

[14] Mobile Payments 2002 - making mobile services pay. Wireless World Forum, 2002.

[15] David Collins, Seung Hwan Choi et al. Mobile Payment in Asia Pacific. Information, Communication and Entertainment, KPMG 2007, www.kpmg.com

\section{AUTHOR}

Rodrigue Carlos Nana Mbinkeu is with National Advanced School of Engineering, University of Yaounde I, 8390 Yaounde, Cameroon and the DBGroupLab - University of Modena, Italy (nanambinkeu@gmail.com)

Received 21 December 2012. Published as resubmitted by the author 20 March 2013. 